\title{
An outbreak of dengue virus (DENV) type 2 Cosmopolitan genotype in Israeli travellers returning from the Seychelles, April 2017
}

Y Lustig ${ }^{1}$, D Wolf ${ }^{2}, \mathrm{O} \mathrm{Halutz}^{3}$, E Schwartz 45

1. Central Virology Laboratory, Ministry of Health, Chaim Sheba Medical Center, Ramat Gan, Israel

2. Clinical Virology Unit, Hadassah Hebrew University Medical Center, Jerusalem, Israel

3. Department of Virology Unit of the Microbiology Laboratory, Dana Dwek Children's Hospital, Tel Aviv Sourasky Medical Center, Tel Aviv, Israel

4. Sackler Faculty of Medicine, Tel-Aviv University, Tel-Aviv, Israel

5. nstitute of Tropical and Travel Medicine, Sheba Medical Center, Tel Hashomer, Ramat-Gan, Israel

Correspondence: Yaniv Lustig (yaniv.lustig@sheba.health.gov.il)

Citation style for this article:

Lustig Y, Wolf D, Halutz O, Schwartz E. An outbreak of dengue virus (DENV) type 2 Cosmopolitan genotype in Israeli travellers returning from the Seychelles, April 2017. Euro Surveill. 2017;22(26):pii=30563. DOI: http://dx.doi.org/10.2807/1560-7917.ES.2017.22.26.30563

Dengue virus infection was diagnosed in six Israeli travellers returning from the Seychelles in April 2017. Phylogenetic analysis identified identical sequences belonging to the Cosmopolitan genotype of dengue virus type 2 in all samples sequenced, thus providing evidence for a probable dengue type 2 outbreak in the Seychelles. This report further demonstrates the role of travellers as sentinels for arboviral infections, especially in countries with limited diagnostic capabilities.

Because of the high number of mosquito species and especially the abundance of Aedes albopictus mosquitoes [1], the Seychelles remain under the threat of outbreaks, particularly arboviruses [2]. However, only limited data are available on the types and molecular characteristics of arboviruses circulating in the region. In this report we investigated an outbreak of dengue virus (DENV) infection in six Israeli travellers returning from the Seychelles, a popular tourist destination located in the Indian ocean east of the East African coast with a population of roughly 90,000 inhabitants.

\section{Dengue diagnosis in Israeli travellers}

Nine Israeli citizens who had travelled to the Seychelles islands reported a febrile illness which started 1-2 days after returning to Israel. They were part of a group of 32 travellers visiting a different island every day between 13 and 22 April 2017. The islands visited, in consecutive order, were: Mahe, Curieuse, Aride, Praslin, La Digue and Moyenne.

In six of the febrile travellers, dengue fever was confirmed, in four of them by both quantitative (q) RT-PCR [3] or PCR [4] and DENV IgM and IgG antibody capture ELISA (Panbio, Brisbane, Australia), in one only by qRT-PCR, and in one only by positive dengue virus NS1 antigen (Panbio, Brisbane, Australia) and IgM and IgG serology (Table). Since DENV RNA in serum can only be detected for a short time after symptom onset [5-8], DENV RNA in urine and whole blood was tested for samples obtained more than 10 days post symptom onset (Table). qRT-PCR of DENV-1-4 [3] or PCR [4] demonstrated that all five PCR-positve cases had DENV type 2. The remaining three febrile patients did not present to our clinics and therefore were not tested for dengue.

Three additional members of this group of travellers suffered from upper respiratory symptoms (one of them was only febrile). They were examined in our clinic, tested for DENV infection (by qRT-PCR, NS1 and serology) and found to be negative. We were not able to test the remaining asymptomatic travellers.

\section{Genetic relationship}

From the four RNA samples positive for DENV in qRT$P C R, 2,450$ nt spanning the capsid, pre-membrane (prM), membrane $(M)$ and envelope (E) genes were amplified [4]. The raw sequence data were analysed and trimmed to generate a 1,429-nt consensus sequence of the E gene, using Sequencher 5.4 (GeneCodes, Ann Arbor, Michigan), and the DENV E gene sequences were aligned with 23 DENV type $2 \mathrm{E}$ gene sequences obtained from the GenBank database. The accession numbers for reference sequences are specified in the Figure. Phylogenetic analysis was conducted using a neighbour-joining algorithm in MEGA, version 6 [9], with 1,000 replicates for bootstrap testing. A neighbour-joining phylogenetic tree based on the aligned sequence data showed that all four DENV 2 sequences from Israeli travellers were identical and clustered with the Cosmopolitan genotype. Most importantly, strains belonging to lineage I of the Cosmopolitan genotype 
Phylogenetic analysis of the envelope gene sequence of DENV type 2 from Israeli travellers, Seychelles, April 2017 ( $\mathrm{n}=4$ )

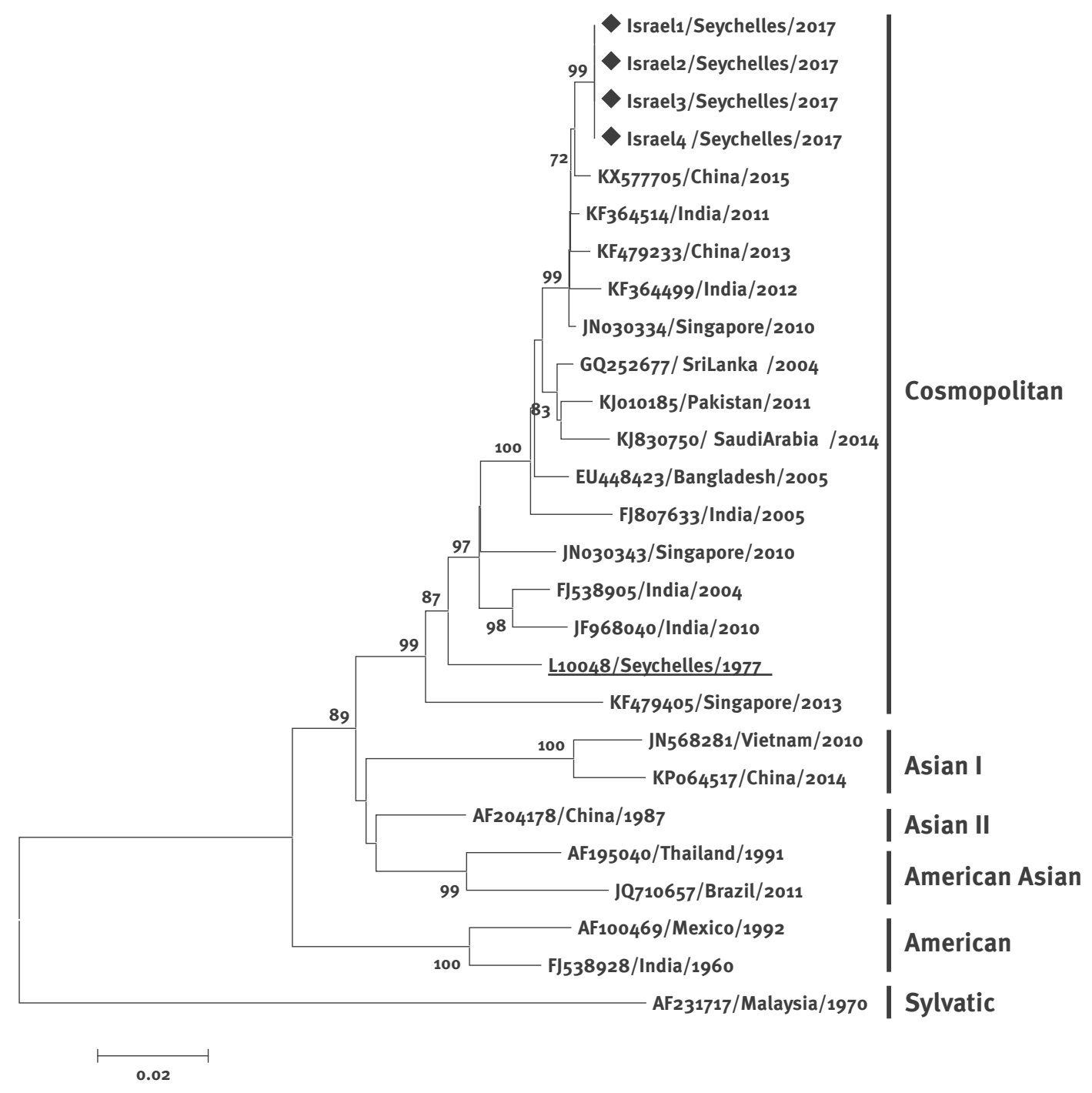

The analysis was conducted on a nucleotide sequence of the genes encoding the E protein (1,429 bp), using the neighbour-joining method implemented in MEGA 6.0 software. The robustness of branching pattern was tested by 1,000 bootstrap replications. The percentage of successful bootstrap replicates is indicated at nodes, showing only values of $>70 \%$. The bar denotes 0.02 nucleotide substitutions per site. DENV strains sequenced in this study are marked by black diamonds. Reference strains are indicated by accession number and place and year of isolation. The DENV type 2 strain isolated in 1977 in the Seychelles is underlined.

from China, India and Singapore were found to cluster with the strains of the present study (Figure).

\section{Discussion}

DENV is currently a leading cause of illness and death in the tropics and subtropics with as many as 400 million people infected yearly [10]. However, because it occurs in many areas with limited diagnostic resources and co-circulates with other arboviruses with similar clinical manifestations, travellers are often the most sensitive sentinels for arboviral outbreaks. Here we report a dengue outbreak in the Seychelles that was revealed by six Israeli travellers diagnosed with acute DENV infection, demonstrating the power of such passive arbovirus surveillance.
Mahe is the largest and most populated island where most of the previous outbreaks in the Seychelles have been reported [11]. Assuming that DENV exposure happened there would result in an incubation time of 10-12 days, which is longer than what is usual for dengue (4-7 days) [12]. Therefore, and because all travellers had disease onset almost on the same day, a simultaneous exposure on one of the other islands is more plausible. The immediate result of this study was an alert through ProMED [13] assuming that this would also alert the Seychelles public health authorities of the possibility of an outbreak on one of the smaller islands. 
Clinical and diagnostic data of dengue virus-infected Israeli travellers, Seychelles, April $2017(\mathrm{n}=6)$

\begin{tabular}{|c|c|c|c|c|c|c|c|}
\hline \multirow[b]{2}{*}{ Patient } & \multirow[b]{2}{*}{ Sex/age group } & \multirow[b]{2}{*}{ Main symptoms (description) } & \multirow{2}{*}{$\begin{array}{l}\text { RT-PCR result }(C t) \\
\text { sample type }\end{array}$} & \multicolumn{4}{|c|}{ Serum sample } \\
\hline & & & & $\begin{array}{l}\text { Time from onset } \\
\text { (days) }\end{array}$ & $\begin{array}{l}\text { NS1 early } \\
\text { antigen }\end{array}$ & $\lg M$ & $\lg G$ \\
\hline 1 & $\mathrm{~F} / 50-59$ & Fever+Rash & Pos (26.7), urine & 14 & Neg & Pos & Pos \\
\hline 2 & $M / 70-79$ & Fever + Pruritus & Pos (26), urine & 16 & Neg & Pos & Pos \\
\hline 3 & $M / 60-69$ & Fever & Pos (31), urine & 15 & Neg & Pos & Pos \\
\hline 4 & $\mathrm{~F} / 70-79$ & Fever+Rash & Neg, serum & 10 & Pos & Pos & Pos \\
\hline 5 & $\mathrm{~F} / 70-79$ & Fever+Rash & Pos (25.6), serum & 6 & ND & ND & ND \\
\hline 6 & $M / 80-89$ & Fever+Rash & Pos ${ }^{a}$, whole blood & 15 & Neg & Pos & Pos \\
\hline
\end{tabular}

F: female; M: male; ND: not done; Neg: negative; Pos: positive.

a Only PCR was performed and therefore no $\mathrm{Ct}$ value is available.

Although DENV RNA was identified in five patients, NS1 antigen was not detected. This is not surprising, since all NS1-negative samples had been obtained more than 12 days after symptom onset and it has been demonstrated previously that samples from dengue patients do not test positive for $\mathrm{NS}_{1}$ later than 12 days post symptom onset [14]. While detection of DENV RNA in serum is also limited to a short time ( $<1$ week) after symptom onset, RNA in urine and whole blood can be detected for a longer period, similarly to other flaviviruses such as West Nile and Zika virus [5-8]. Indeed, in our patients, urine and whole blood samples obtained more than 14 days post symptom onset were positive for DENV RNA.

During the past 5 years, two outbreaks of dengue or dengue-like symptoms have been documented in the Seychelles and both DENV types 1 and 2 have been identified [11]. However, DENV was isolated only once in 1977 (GenBank accession number: L10048) and found to be type 2 [15]. Phylogenetic analysis performed in 1999 identified that this 1977 DENV strain was most similar to dengue 2 strains isolated in Delhi, India in 1996 [16]. Our data demonstrate that the 1977 isolate similarly to the 2017 isolates, belonged to the Cosmopolitan genotype. It is tempting to speculate that the Cosmopolitan genotype has continued to circulate in the Seychelles from the 1970s until now. However, because the phylogeny differed considerably between the current and former DENV-2 strains from the Seychelles and similar cosmopolitan strains were identified in China in 2013 and 2015 and in India in 2011-12, we hypothesise that the DENV responsible for the current outbreak was imported from a country endemic for Cosmopolitan DENV-2.

\section{Conclusion}

This study identified a DENV outbreak in the Seychelles. The diagnosis of six individuals with DENV infection among 32 Israeli travellers suggests that there is considerable circulation of DENV in mosquitoes in the Seychelles. Future monitoring of DENV circulation in mosquitoes in this area should reveal the extent of penetration of DENV and other arboviruses in the Seychelles and will contribute considerably to the epidemiological characterisation of these zoonotic viruses.

\section{Acknowledgements}

Financial Support: This work was supported by internal sources of the Central Virology Laboratory.

Conflict of interest

None declared.

\section{Authors' contributions}

Y.L. contributed to the study design, performed the molecular experiments, analysed the data, wrote and edited the manuscript, D.W and O.H contributed to the study design and edited the manuscript, E.S coordinated the work, analysed the data, contributed to the study design and provided critical review of the manuscript.

\section{References}

1. Le Goff G, Boussès P, Julienne S, Brengues C, Rahola N, Rocamora G, et al. The mosquitoes (Diptera: Culidae) of Seychelles: taxonomy, ecology, vectorial importance, and identification keys. Parasit Vectors. 2012;5(1):207. DOI: 10.1186/1756-3305-5-207 PMID: 22999320

2. Bovet $P$, Gedeon J, Louange M, Durasnel P, Aubry P, Gauzere $B A$. [Health situation and issues in the Seychelles in 2012.]Med Sante Trop. 2013;23(3):256-66. French.

3. Waggoner JJ, Abeynayake J, Sahoo MK, Gresh L, Tellez Y, Gonzalez K, et al. Comparison of the FDA-approved CDC DENV-1-4 real-time reverse transcription-PCR with a laboratorydeveloped assay for dengue virus detection and serotyping. J Clin Microbiol. 2013;51(10):3418-20. DOI: 10.1128/JCM.01359-13 PMID: 23903549

4. Cruz CD, Torre A, Troncos G, Lambrechts L, Leguia M. Targeted full-genome amplification and sequencing of dengue virus types 1-4 from South America.J Virol Methods. 2016;235:15867. DOI: 10.1016/j.jviromet.2016.06.001 PMID: 27334982

5. Gourinat AC, O'Connor O, Calvez E, Goarant C, DupontRouzeyrol M. Detection of Zika virus in urine.Emerg Infect Dis. 2015;21(1):84-6. DOI: 10.3201/eid2101.140894 PMID: 25530324

6. Hirayama T, Mizuno Y, Takeshita N, Kotaki A, Tajima S, Omatsu $T$, et al. Detection of dengue virus genome in urine by real-time reverse transcriptase PCR: a laboratory diagnostic method useful after disappearance of the genome in serum. J 
Clin Microbiol. 2012;50(6):2047-52. DOI: 10.1128/JCM.06557-11 PMID: 22442323

7. Lustig Y, Mannasse B, Koren R, Katz-Likvornik S, Hindiyeh $M$, Mandelboim M, et al. Superiority of West Nile Virus RNA Detection in Whole Blood for Diagnosis of Acute Infection. J Clin Microbiol. 2016;54(9):2294-7. DOI: 10.1128/JCM.01283-16 PMID: 27335150

8. Lustig Y, Mendelson E, Paran N, Melamed S, Schwartz E. Detection of Zika virus RNA in whole blood of imported Zika virus disease cases up to 2 months after symptom onset, Israel, December 2015 to April 2016. Euro Surveill. 2016;21(26):30269. DOI: 10.2807/1560-7917. ES.2016.21.26.30269 PMID: 27386894

9. Tamura K, Stecher G, Peterson D, Filipski A, Kumar S. MEGA6: Molecular Evolutionary Genetics Analysis version 6.0.Mol Bio Evol. 2013;30(12):2725-9. DOI: 10.1093/molbev/mst197 PMID: 24132122

10. Ayukekbong JA, Oyero OG, Nnukwu SE, Mesumbe HN, Fobisong CN. Value of routine dengue diagnosis in endemic countries. World J Virol. 2017;6(1):9-16. DOI: 10.5501/wjv.v6.i1.9 PMID: 28239567

11. Sandin A. Emergency plan of action final report Seychelles: dengue outbreak. Geneva: International Federation of Red Cross and Red Crescent Societies; 2016. Available from: http://reliefweb.int/sites/reliefweb.int/files/resources/ MDRSC004fnr.pdf

12. Wilder-Smith A, Schwartz E. Dengue in travelers.N Engl J Med. 2005;353(9):924-32. DOI: 10.1056/NEJMra041927 PMID: 16135837

13. ProMED-mail. Dengue/DHF update (06): Israel ex Seychelles. Archive Number 20170531.5073985. 30 May 2017. Available from: 31.05.17. http://www.promedmail.org/direct. php?id=20170531.5073985

14. Fuchs I, Bin H, Schlezinger S, Schwartz E. NS1 antigen testing for the diagnosis of dengue in returned Israeli travelers.J Med Virol. 2014;86(12):2005-10. DOI: 10.1002/jmv.23879 PMID: 24390973

15. Lewis JA, Chang GJ, Lanciotti RS, Kinney RM, Mayer LW, Trent DW. Phylogenetic relationships of dengue-2 viruses.Virology. 1993;197(1):216-24. DOI: 10.1006/viro.1993.1582 PMID: 8212556

16. Singh UB, Maitra A, Broor S, Rai A, Pasha ST, Seth P. Partial nucleotide sequencing and molecular evolution of epidemic causing Dengue 2 strains.J Infect Dis. 1999;180(4):959-65. DOI: 10.1086/315043 PMID: 10479118

\section{License and copyright}

This is an open-access article distributed under the terms of the Creative Commons Attribution (CC BY 4.0) Licence. You may share and adapt the material, but must give appropriate credit to the source, provide a link to the licence, and indicate if changes were made.

This article is copyright of the authors, 2017. 